\title{
Dropping out of dialectical behaviour therapy in the NHS: the role of care coordination
}

\author{
Amy Gaglia, ${ }_{1}^{1}$ Jurgen Essletzbichler, ${ }^{2}$ Kirsten Barnicot, ${ }^{3}$ Nyla Bhatti, ${ }^{3}$ Stefan Priebe ${ }^{3}$
}

The Psychiatrist (2013), 37, 267-271, doi: 10.1192/pb.bp.112.041251

${ }^{1}$ East London NHS Foundation Trust: ${ }^{2}$ University College London; ${ }^{3}$ Newham Centre for Mental Health, London

Correspondence to Amy Gaglia (amy.gaglia@eastlondon.nhs.uk)

First received 11 Sep 2012, final revision 25 Feb 2013, accepted 8 Mar 2013

\begin{abstract}
Aims and method Dialectical behaviour therapy (DBT) is associated with particularly high drop-out rates in the National Health Service (NHS). This paper seeks to investigate the characteristics of patients with borderline personality disorder dropping out from DBT and the role of care coordination in this phenomenon. Data for the 102 patients receiving DBT in east London, 58\% of whom had dropped out of treatment prematurely, were analysed.
\end{abstract}

Results In a multivariable analysis, a history of care coordination was the only variable significantly correlated with drop out: $88 \%$ of patients with a history of care coordination dropped out prematurely compared with $52 \%$ of patients without such history.

Clinical implications The experience of comprehensive care within the care programme approach, particularly care coordination at the start of DBT, affects the retention of patients in DBT. Further qualitative research is required to understand how care coordination and DBT drop out are related, which could lead to changes in how the therapy is delivered in the UK and influence decisions regarding the use of care coordination with patients with borderline personality disorder.

Declaration of interest None.
Dialectical behaviour therapy (DBT) is an evidence-based intensive treatment for borderline personality disorder and self-harm created by Linehan. In its original form it offers a year-long treatment consisting of 2-2.5 hours per week of group-based skills training, 1 hour a week of a one-to-one session, the opportunity for between-session crisis skills coaching and weekly peer supervision for the treatment team. ${ }^{1,2}$ Randomised controlled trials (RCTs) in the USA, The Netherlands and the UK have demonstrated that DBT is effective at helping people reduce self-harming behaviour. $^{3-9}$ The average treatment retention rate in non-UK-based studies was $67 \%$. However, the UK-based RCTs comparing DBT with treatment as usual ${ }^{3,10}$ demonstrated much higher treatment drop-out rates: 58 and $52 \%$, whereas an earlier UK-based observational study reported an even higher drop-out rate of $67 \% .^{11}$ The McMain et $a l^{7}$ study of treatment as usual $v$. DBT in Canada also had a relatively high drop-out rate of $39 \%$.

Previous studies on drop out and disengagement from mental health services identified associations with socioeconomic characteristics such as younger age, male gender, ethnic minority background, low socioeconomic status and social isolation. ${ }^{12,13}$ Those studies also linked clinical characteristics such as substance misuse, forensic history, high levels of psychopathology and lack of insight to higher drop-out rates. Some research has found poor alliance with the therapist as well as a lack of active participation in treatment by the patient to be correlated with drop out. ${ }^{14,15}$ Drop out is more likely to occur during the early period of treatment. ${ }^{12,13}$ In contrast to those studies, Barnicot et al's ${ }^{16}$ meta-analysis on drop out for patients with borderline personality disorder revealed that sociodemographic variables are consistently non-significantly associated with drop out for this group of patients, whereas lower commitment to change, a poorer therapeutic relationship, and higher impulsivity consistently predicted drop out. Other work has shown that patients with borderline personality disorder who perceive their treatment as less credible, do not use the skills taught in therapy, and have lower self-efficacy, and are also more likely to drop out of DBT (further details from K.B., on request).

McMain et $a l^{7}$ put down treatment context as a possible explanatory factor for their high drop-out rate - and specifically, the availability of other publicly funded treatment options - and Priebe et $a l^{10}$ speculated that the National Health Service (NHS) context might lead to higher drop-out rates since alternative treatments or (crisis) management options are more easily available in the UK than in other settings, such as the healthcare system in the USA. Yet, no further research has been conducted to explore this. The current study examines the characteristics of patients dropping out from DBT in the UK and focuses on the question of whether being the recipient of care coordination under the care programme approach at the start of treatment leads to higher drop-out rates from DBT. A person with complex needs who is involved with multiple services (Social Services, mental health services, etc.) and who has a history of risky behaviour, such as suicide 
attempts or harm to others, may be appointed a key worker who monitors mental health symptoms and risk and coordinates care by meeting regularly with the individual. ${ }^{17}$ In line with the suggestion of McMain et $a l^{7}$ it may be possible that patients who have received care coordination will have learnt to rely on the care coordination system. Thus, they will be, first, more attuned to management of symptoms rather than change, which could lead to dissatisfaction with the change-oriented aspect of DBT, and second, aware that the care coordination system will be there for them as a 'fallback' should they drop out of therapy. To get a better understanding of the role of treatment context on drop out and because the link between care coordination and drop out from DBT has not been investigated yet, this study aims to address two questions:

1 What are the characteristics of patients dropping out from DBT?

2 How important is care coordination status to explain drop out from DBT?

\section{Method}

The study included data of 102 patients who were offered 1 year of DBT from a specialised team in the London Borough of Newham between 2008 and 2011; the drop-out rate for this group was $58 \%$. Inclusion criteria for DBT were self-harming behaviour, defined as intentional tissue damage, on at least 5 days in the previous year, and a diagnosis of at least one personality disorder. Participants were all referred from either primary or secondary mental healthcare services.

To identify possible factors influencing drop out from DBT (measured as a binary variable: yes $=1$; no $=0$ ), a range of variables were selected based on predicators of outcome for borderline personality disorder identified in Gunderson et al's study. ${ }^{18}$ Personality disorder as identified through SCID-II screening, ${ }^{19}$ a diagnosis of depression or posttraumatic stress disorder (PTSD; assessed through the Mini-International Neuropsychiatric Interview ${ }^{20}$ (MINI) are measured as binary variables (conditions identified: yes $=1 ;$ no $=0$ ). History of hospitalisation, sectioning, substance misuse and psychotherapy were retrieved from patients' medical histories and coded as ' 1 ' if those factors were present and ' 0 ' if absent. Trauma history was identified as a stated history of emotional, physical or sexual abuse and was also coded as a binary variable (yes $=1$; no $=0$ ). Time in secondary care prior to starting DBT is measured as the number of months in secondary care. Incidence of self-harm and intended suicide attempts are measured in number of attempts during the year prior to treatment commencement. Severity of mental health symptoms on the Brief Psychiatric Rating Scale (BPRS), ${ }^{21}$ the Brief Symptom Inventory $^{22}$ and Zanarini ${ }^{23}$ score for severity of borderline personality disorder symptoms at baseline are based on administered questionnaires.

Our main variable of interest was a history of care coordination. Two indicators of care coordination status were available from patients' records. First, whether patients received care coordination some time in the past, and second, whether patients still received it at the beginning of treatment (a subset of the first group). Based on our hypothesis that care coordination may result in less commitment to change, we would expect only those patients that had care coordination at the time of treatment entry to be affected by higher drop-out rates. Hence, care coordination status at treatment commencement was used in this study and coded as a binary variable (yes $=1$; no $=0$ ). This choice was further supported by Fischer's exact tests revealing that the drop-out rates of the 5 patients no longer in care coordination did not differ significantly from those of patients that never received care coordination $(P=1.000)$, whereas those 17 patients who did receive care coordination when entering DBT had significantly higher drop-out rates $(P=0.006)$, as almost $90 \%$ of this group dropped out. Although information on care coordinators or length of care coordination was not available, information on time in treatment was available for the majority of patients. Time in treatment was measured as the total number of contact hours.

Finally, a number of socioeconomic characteristics such as age, gender, ethnicity and employment status at baseline were also tested for their relationship to drop out. We then further compared the sociodemographic and clinical characteristics of patients with and without care coordination to get a better understanding of how the two groups may differ (detailed results available from the authors on request).

\section{Statistical analysis}

The association of each of those factors with drop out was first established using $t$-tests and $\chi^{2}$-tests. The results constituted the basis for building a multivariate logistic regression model in which all variables were included with a univariable association with drop out that was significant at the $P<0.1$ level. This included care coordination at the start of DBT treatment, a history of significant substance misuse, gender, and a diagnosis of obsessive-compulsive personality disorder (OCPD). To gain a better understanding of the impact of care coordination on the timing of drop out, Kaplan-Meier curves are provided for the two groups of patients.

\section{Results}

Over the 1 year studied, 59 patients dropped out of treatment. Table 1 shows the sociodemographic and clinical characteristics of the total sample, those who completed the treatment and those who dropped out, as well as the results of the statistical comparison of the groups.

Table 1 reveals that men tended to drop out of treatment more often, whereas patients with OCPD were more likely to complete treatment (trend). The two groups showed statistically significant differences with respect to a history of care coordination and of substance misuse: $88 \%$ $(n=15)$ of patients who received care coordination at the start of treatment $(n=17)$ dropped out as compared with $52 \% \quad(n=44)$ of those without such a history $(n=85)$ $\left(\chi^{2}=7.73, P \leqslant 0.01\right)$. Drop-out rates for patients who had received care coordination in the past, but have no longer done so at the beginning of DBT treatment did not differ significantly from those that had never received care coordination and were thus not classified as 'care coordinated'. Only those patients who still had care coordination at the start of treatment were classified as such. Regarding history of substance misuse, $73 \%(n=22)$ of patients with a history of substance misuse $(n=30)$ dropped 


\begin{tabular}{|c|c|c|c|c|}
\hline \multirow[b]{2}{*}{ Characteristics } & \multicolumn{3}{|c|}{$\%$} & \multirow{2}{*}{$\begin{array}{c}\text { Difference } \\
\text { dropped out/completers } \\
\chi^{2} / t(P)\end{array}$} \\
\hline & $\begin{array}{c}\text { All } \\
(n=102)\end{array}$ & $\begin{array}{l}\text { Dropped out } \\
\quad(n=59)\end{array}$ & $\begin{array}{l}\text { Completers } \\
(n=43)\end{array}$ & \\
\hline $\begin{array}{l}\text { Gender } \\
\text { Male } \\
\text { Female }\end{array}$ & $\begin{array}{l}11.8 \\
88.2\end{array}$ & $\begin{array}{l}16.9 \\
83.1\end{array}$ & $\begin{array}{r}4.7 \\
95.3\end{array}$ & $3.62(0.06)$ \\
\hline Age, years: mean & 32.4 & 32.8 & 31.9 & $-0.43(0.67)$ \\
\hline $\begin{array}{l}\text { Ethnicity } \\
\text { White } \\
\text { Black } \\
\text { South Asian } \\
\text { East Asian } \\
\text { Mixed } \\
\end{array}$ & $\begin{array}{r}61.8 \\
13.7 \\
18.6 \\
2.0 \\
3.9 \\
\end{array}$ & $\begin{array}{r}62.7 \\
10.2 \\
20.3 \\
1.7 \\
5.1 \\
\end{array}$ & $\begin{array}{r}60.5 \\
18.6 \\
16.3 \\
2.3 \\
2.3 \\
\end{array}$ & $2.10(0.72)$ \\
\hline $\begin{array}{l}\text { Employment } \\
\text { Out of work } \\
\text { Voluntary/sheltered } \\
\text { Regular } \\
\end{array}$ & $\begin{array}{r}62.7 \\
8.8 \\
28.4 \\
\end{array}$ & $\begin{array}{l}64.4 \\
10.2 \\
25.4 \\
\end{array}$ & $\begin{array}{r}60.5 \\
7.0 \\
32.6 \\
\end{array}$ & $0.79(0.67)$ \\
\hline $\begin{array}{l}\text { Living situation } \\
\text { Living alone } \\
\text { With partner/family }\end{array}$ & $\begin{array}{l}32.7 \\
67.3 \\
\end{array}$ & $\begin{array}{l}35.5 \\
65.5\end{array}$ & $\begin{array}{l}30.2 \\
69.8 \\
\end{array}$ & $0.20(0.65)$ \\
\hline $\begin{array}{l}\text { History of: } \\
\text { Care coordination } \\
\text { Hospitalisation } \\
\text { Sectioning } \\
\text { Psychotherapy } \\
\text { Trauma (emotional, physical or sexual abuse) } \\
\text { Significant substance misuse } \\
\end{array}$ & $\begin{array}{r}16.7 \\
43.1 \\
9.8 \\
62.8 \\
89.2 \\
29.4 \\
\end{array}$ & $\begin{array}{r}25.4 \\
47.5 \\
7.0 \\
67.8 \\
91.5 \\
37.3 \\
\end{array}$ & $\begin{array}{r}4.7 \\
37.2 \\
11.9 \\
53.5 \\
86.1 \\
18.6 \\
\end{array}$ & $\begin{array}{l}7.73(<0.01) \\
1.07(0.30) \\
0.67(0.41) \\
2.16(0.14) \\
0.78(0.38) \\
4.18(0.04) \\
\end{array}$ \\
\hline $\begin{array}{l}\text { Diagnosis of personality disorder }(\mathrm{SCID}-\mathrm{II})^{\mathrm{a}} \\
\text { Avoidant } \\
\text { Dependent } \\
\text { Obsessive-compulsive } \\
\text { Paranoid } \\
\text { Schizotypal } \\
\text { Schizoid } \\
\text { Histrionic } \\
\text { Narcissistic } \\
\text { Borderline } \\
\text { Antisocial }\end{array}$ & $\begin{array}{r}62.8 \\
23.5 \\
46.1 \\
49.0 \\
14.7 \\
6.9 \\
2.0 \\
12.8 \\
99.0 \\
19.6 \\
\end{array}$ & $\begin{array}{r}67.8 \\
25.3 \\
39.0 \\
50.9 \\
15.3 \\
6.8 \\
1.7 \\
13.6 \\
100.0 \\
23.7 \\
\end{array}$ & $\begin{array}{r}55.8 \\
20.9 \\
55.8 \\
46.5 \\
14.0 \\
7.0 \\
2.3 \\
11.6 \\
97.7 \\
14.0 \\
\end{array}$ & $\begin{array}{l}1.53(0.22) \\
0.28(0.60) \\
2.84(0.09) \\
0.19(0.67) \\
0.03(0.86) \\
0.00(0.97) \\
0.05(0.82) \\
0.08(0.77) \\
1.39(0.24) \\
1.51(0.22)\end{array}$ \\
\hline Depression $(\mathrm{MINI})^{\mathrm{a}}$ & 76.5 & 80.0 & 72.1 & $0.79(0.37)$ \\
\hline Post-traumatic stress disorder & 53.9 & 54.2 & 53.5 & $0.01(0.94)$ \\
\hline Time in secondary care before DBT, months: mean & 21.4 & 24.4 & 17.4 & $-1.55(0.12)$ \\
\hline $\begin{array}{l}\text { Baseline tests, mean } \\
\text { Incidence of self-harm } \\
\text { Suicide attempts } \\
\text { Zanarini } \\
\text { BPRS }^{\mathrm{c}} \\
\text { BSI }^{\mathrm{C}}\end{array}$ & $\begin{array}{r}85.0 \\
2.3 \\
17.3 \\
51.2 \\
124.4\end{array}$ & $\begin{array}{r}75.7 \\
3.0 \\
17.4 \\
50.5 \\
124.9\end{array}$ & $\begin{array}{r}97.6 \\
1.4 \\
17.2 \\
52.3 \\
123.3\end{array}$ & $\begin{array}{r}\mathbf{0 . 9 7}(0.34) \\
-\mathbf{1 . 3 7}(0.18) \\
-\mathbf{0 . 1 1}(0.91) \\
\mathbf{1 . 0 8}(0.28) \\
-\mathbf{0 . 1 4}(0.89)\end{array}$ \\
\hline
\end{tabular}

BPRS, Brief Psychiatric Rating Scale; BSI, Brief Symptom Inventory; DBT, dialectical behaviour therapy; MINI, Mini-International Nueropsychiatric Interview. Values in bold are $\chi^{2}$ as opposed to $t$-values.

a. Measured as binary variables (yes $=1 ;$ no $=0$ )

b. Number of attempts during year prior to the start of treatment.

c. Based on administered questionnaires.

out as compared with $51 \%(n=37)$ of patients without $(n=72) \quad\left(\chi^{2}=4.18, P=0.04\right)$. Of patients diagnosed with OCPD $(n=47), 49 \%(n=23)$ dropped out as compared with $65 \%(n=36)$ of those who did not have that diagnosis $(n=55)$. Patients receiving care coordination were more likely to be hospitalised $\left(\chi^{2}=21.62, P<0.01\right)$ and sectioned $\left(\chi^{2}=8.87, P<0.01\right)$ in the past, spent twice as many days in secondary care $(t=-3.25, P<0.01)$ and were six times more likely to attempt suicide $(t=-3.18, P<0.01)$. Care coordination was not related to any sociodemographic characteristics or diagnoses (SCID-II), but patients who received it had lower Zanarini scores for symptom severity of borderline personality disorder at baseline $(t=1.78$, $P=0.08$ ). Care coordination is thus associated with a number of variables indicating risky behaviour and tends to include patients with lower symptom severity of borderline personality disorder.

Table 2 reports the results of the multivariate logistic regression analysis ((pseudo) $R^{2}=0.11$; model $\chi^{2}(4)=15.51$ ) revealing that care coordination history was the only predictor variable to remain statistically significant $(B=1.77 ; P=0.03$; odds ratio $(\mathrm{OR})=5.86)$, whereas substance 


\begin{tabular}{|c|c|c|c|}
\hline \multirow[t]{2}{*}{ Table 2} & \multicolumn{3}{|c|}{$\begin{array}{l}\text { Relationship between drop out, care } \\
\text { coordination status, substance misuse history, } \\
\text { gender and OCPD diagnosis: results from } \\
\text { logistic regression }\end{array}$} \\
\hline & & & $\mathrm{but}^{\mathrm{a}}$ \\
\hline \multicolumn{2}{|l|}{ Variables } & $\begin{array}{l}\text { Parameter } \\
\text { estimates }(P)\end{array}$ & $\begin{array}{l}\text { Odds ratio } \\
(95 \% \mathrm{Cl})\end{array}$ \\
\hline \multicolumn{2}{|l|}{ Constant } & $2.08(0.22)$ & - \\
\hline \multicolumn{2}{|c|}{ Care coordination $^{a}$} & $1.77(0.03)$ & $5.86(1.22-28.17)$ \\
\hline \multicolumn{2}{|c|}{$\begin{array}{l}\text { Significant substance } \\
\text { misuse }^{a}\end{array}$} & $0.77(0.14)$ & $2.16(0.78-5.97)$ \\
\hline \multicolumn{2}{|c|}{ Gender $^{\mathrm{b}}$} & $-1.03(0.23)$ & $0.36(0.07-1.93)$ \\
\hline \multicolumn{2}{|l|}{$\mathrm{OCPD}^{\mathrm{a}}$} & $-0.50(0.26)$ & $0.61(0.26-1.43)$ \\
\hline \multicolumn{2}{|c|}{$\begin{array}{l}\text { Log likelihood } \\
\text { Model } \chi^{2} \text { (d.f.) }\end{array}$} & \multicolumn{2}{|c|}{$\begin{array}{c}-61.68 \\
15.51(4) \\
P=0.004\end{array}$} \\
\hline \multicolumn{2}{|l|}{$N$} & \multicolumn{2}{|c|}{102} \\
\hline
\end{tabular}

OCPD, obsessive-compulsive personality disorder.

a. Binary variables: yes $=1$, no $=0$.

b. Male $=1$, female $=2$.

misuse history $(B=0.77 ; \quad P=0.14 ; \quad \mathrm{OR}=2.16)$, gender $(B=-1.03 ; \quad P=0.23 ; \quad \mathrm{OR}=0.36) \quad$ and $\mathrm{OCPD} \quad(B=-0.50$; $P=0.26$; OR $=0.61)$ were no longer statistically significant. The results indicate that the odds of a patient who receives care coordination dropping out are 5.86 times higher than the odds of a patient who does not receive it.

To get a better understanding of how care coordination affects the pattern of drop out, Fig. 1 depicts the KaplanMeier survival curves by care coordination status. Although both groups experience fast rates of drop out during the early stages of treatment (probability to remain in treatment for each group is $80 \%$ after 5 hours, including 2 hours of assessment), drop out occurs at a much more rapid pace for the 'care coordinated' group at between 5 and 11 hours of treatment. At 9 treatment hours, the probability to remain in treatment drops to $53 \%$ for patients receiving care coordination compared with $80 \%$ for the group who do not. At 11 hours, probabilities drop to $33.3 \%$ and $78 \%$ respectively.

\section{Discussion}

Historically, people with borderline personality disorder were reported to have low treatment completion rates, particularly in psychological therapies that were not tailored to treating the disorder, with one study reporting an $8 \%$ completion rate. $^{24}$ In the past two decades, however, treatments have been created specifically for borderline personality disorder. Average treatment completion rates for these treatments (DBT, mentalisation-based therapy, transference-focused psychotherapy) are $71-75 \% .{ }^{16}$ However, as reported earlier, the much lower completion rates in several more recent studies conducted in the UK are inconsistent with this.

A high drop-out rate affects patients and service providers alike. For patients, it may mean increased hopelessness, frustration and perhaps even a sense of one's illness being untreatable. High drop-out rates also negatively affect service providers and are disheartening to therapists who are trained in specific models of treatment, particularly in DBT, which has as one of its goals keeping people in treatment. ${ }^{1}$

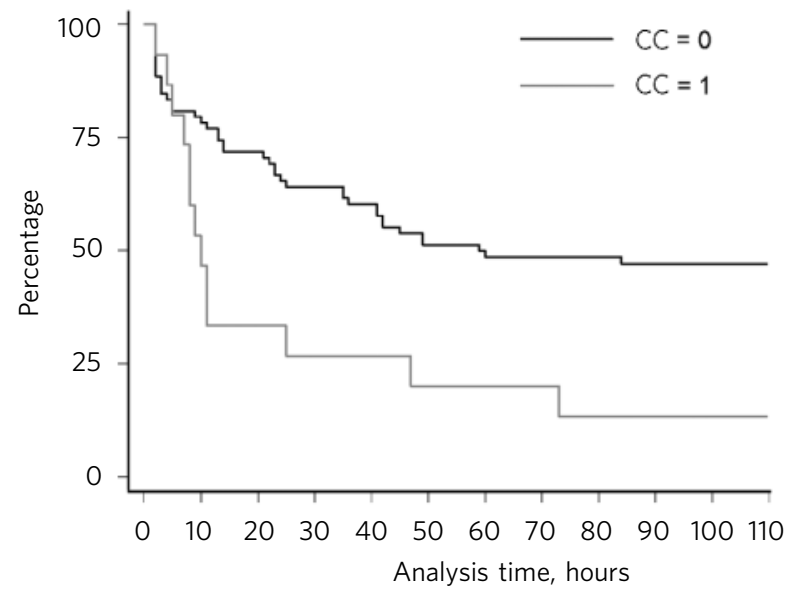

Fig 1 Kaplan-Meier survival curves by care coordination status. CC, care coordination (yes $=1$, no $=0$ ).

This study is consistent with other results on treatment drop out for patients with borderline personality disorder and reveals that sociodemographic characteristics, with the exception of gender, are not associated with drop out (see O'Brien et $\mathrm{al}^{13}$ and Table 1). A history of care coordination was a significant predictor of drop out in this sample and the predictive association was not explained by the influence of other sociodemographic and clinical variables tested. Although drop-out rates tend to be higher during the early stages of treatment for all patients, the analysis revealed that they increased much more rapidly for patients receiving care coordination during the early treatment period. Care coordination is arguably more oriented towards helping patients manage rather than treat or change the mental health symptoms and can provide the experience of comprehensive and always available care.

The predictive value of the history of care coordination in this study might explain the difference in drop-out rates between studies in the USA and the UK, because the treatment-as-usual condition is different in the USA. Not taking up an offer of DBT in the USA often means not having any service. Although case management does exist in the USA, it is not as readily available as it is in the UK and there is no safety net of a universal healthcare system that will always provide some level of care. McMain et $a l^{7}$ raised a similar issue when discussing the relatively high treatment drop-out rate found in their study of DBT $v$. treatment as usual in the Canadian healthcare context, where they stated that they believed high drop out might have something to do with the availability of 'quality' publicly funded alternatives to DBT.

Thus, with such a stark drop-out rate related at least in part to care coordination, we are left with the question of whether care coordination, as it is currently delivered, helps or hinders people with borderline personality disorder. More research is needed into the effects of care coordination as the risk issues associated with people with borderline personality disorder and at times the chaotic social situations that many with borderline personality disorder find themselves in are often managed through care coordination. Further research may also consider whether DBT could be adapted for the NHS context to more effectively address any effects of a history of care coordination. For example, it might be possible to 
develop or modify DBT treatment preparation done by care coordinators and DBT therapists to specifically ameliorate any unintended deleterious effects of care coordination. It is also possible that DBT's strict attendance rules may not be as effective in the NHS context as they were in the USA, but more research on DBT in the NHS would be needed to establish this.

The strengths of the study are that we considered a wide range of sociodemographic and clinical variables as potential predictors. Limitations are that the predominantly female gender mix was not ideal to test the influence of gender, and that the sample size was not very large, although still substantial for this type of research. ${ }^{1}$ The most significant limitation of this study is the lack of detailed quantitative and qualitative information about the care coordination experience. No information about the care coordinators, the nature of the care coordination process (i.e. frequency of contact or issues covered in the contact) and the length of time patients were receiving care coordination as well as a lack of explicit information on patient-stated reasons for dropping out from DBT limits the interpretation of the role of care coordination for DBT drop out.

Data on DBT in the NHS consistently report higher drop-out rates than in the US-based studies. However, the drop-out rate among patients without a history of care coordination in our study was still high at $52 \%$. One can only speculate as to whether, and if so, to what extent, the availability of alternative management/treatments has contributed to dropping out in this group, too. Although these patients have not experienced care coordination themselves, many of them will have been aware of additional treatment options in primary and secondary care. The statistical relationship between care coordination and DBT drop out flags up an important area for future research, including more detailed quantitative and qualitative work to investigate the role of care coordination in patients' behaviour and whether they have learnt to rely on care coordination system, and thus, (1) will be more attuned with the management of symptoms rather than change, or (2) will be aware that the care coordination system will be there as a 'fallback' option if they drop out of treatment. Once we establish the exact link between care coordination and drop out, further research should also explore how DBT can be modified to increase retention rates in the NHS, particularly for patients with a history of care coordination, and possibly develop more appropriate interventions for this patient group as a whole.

\section{About the authors}

Amy Gaglia is a psychotherapist at East London NHS Foundation Trust; Jurgen Essletzbichler is a senior lecturer at University College London; Kirsten Barnicot and Nyla Bhatti are researchers and Stefan Priebe is a professor at the Unit for Social and Community Psychiatry, Newham Centre for Mental Health, London.

\section{References}

1 Linehan MM. Cognitive-Behavioral Treatment of Borderline Personality Disorder. Guilford Press, 1993.

2 Linehan MM. Skills Training Manual for Treating Borderline Personality Disorder. Guilford Press, 1993.

3 Feigenbaum JD, Fonagy $P$, Pilling $S$, Jones $A$, Wildgoose $A$, Bebbington $P E$. A real-world study of the effectiveness of DBT in the UK National Health Service. Br J Clin Psychol 2012; 51: 121-41.
4 Koons CR, Robins CJ, Tweed JL. Efficacy of dialectical behaviour therapy in women veterans with borderline personality disorder. Behav Ther 2001; 32: 371-90.

5 Linehan MM, Armstrong HE, Suarez A, Allmon D, Heard HL. Cognitivebehavioral treatment of chronically parasuicidal borderline patients. Arch Gen Psychiatry 1991; 48: 1060-4.

6 Linehan MM, Schmidt H, Dimeff LA, Craft JC, Kanter J, Comtois KA. Dialectical behavior therapy for patients with borderline personality disorder and drug-dependence. Am J Addict 1999; 8: 279-92.

7 McMain SF, Links PS, Gnam WH, Guimond T, Cardish RJ, Korman L, et al. A randomized trial of dialectical behavior therapy versus genera psychiatric management for borderline personality disorder. Am Psychiatry 2009; 166: 1365-74

8 Turner RM. Naturalistic evaluation of dialectical behavior therapyoriented treatment for borderline personality-disorder for borderline personality disorder. Cog Behav Pract 2000; 7: 413-9.

9 Verheul R, Van Den Bosch LMC, Koeter MWJ, De Ridder MAJ, Stijnen T, Van Den Brink W. Dialectical behaviour therapy for women with borderline personality disorder: 12-month, randomised clinical trial in The Netherlands. Br J Psychiatry 2003; 182: 135-40.

10 Priebe S, Bhatti N, Barnicot K, Bremmer S, Gaglia A, Katsakou C, et al. Effectiveness and cost-effectiveness of dialectical behaviour therapy for self-harming patients with personality disorder: a pragmatic randomised controlled trial. Psychother Psychosom 2012; 81: 356-65.

11 Zinkler M, Gaglia A, Arokiadass SMR, Farhy E. Dialectical behaviour treatment: implementation and outcomes. Psychiatr Bull 2007; 31: 249-52.

12 Kreyenbuhl J, Nossel IR, Dixon LB. Disengagement from mental health treatment among individuals with schizophrenia and strategies for facilitating connections to care: a review of the literature. Schizophr Bull 2009: 35: 696-703.

13 O'Brien A, Fahmy R, Singh SP. Disengagement from mental health services: a literature review. Soc Psychiatry Psychiatr Epidemiol 2009; 44 $558-68$

14 Priebe S, Watts J, Chase M, Matanov A. Processes of disengagement and engagement in assertive outreach patients: qualitative study. $\mathrm{Br} J$ Psychiatry 2005; 187: 438-43.

15 Young AS, Grusky O, Jordan D, Belin TR. Routine outcome monitoring in a public mental health system: the impact of patients who leave care. Psychiatr Serv 2000; 51: 85-91.

16 Barnicot K, Katsakou C, Marougka S, Priebe S. Treatment completion in psychotherapy for borderline personality disorder - a systematic review and meta-analysis. Acta Psychiatr Scand 2011: 1223: 327-38.

17 Department of Health. Effective Care Coordination in Mental Health Services: Modernising the Care Programme Approach (A Policy Booklet). Department of Health, 1999 (http://www.cpaa.org.uk/uploads/1/2/1/ 3/12136843/effective_care_coordination_1999.pdf).

18 Gunderson JG, Daversa MT, Grilo CM, McGlashan TH, Zanarini MC, Shea MT, et al. Predictors of 2-year outcome for patients with borderline personality disorder. Am J Psychiatry 2006; 163: 822-6.

19 First MB, Gibbon M, Spitzer RL, Williams JBW, Benjamin LS. Structured Clinical Interview for DSM-IV Axis II Personality Disorders (SCID-II). American Psychiatric Press, 1997.

20 Sheehan DV, Lecrubier Y, Sheehan KH, Amorim P, Janavs J, Weiller E, et al. The Mini-International Neuropsychiatric Interview (M.I.N.I.): the development and validation of a structured diagnostic psychiatric interview for DSM-IV and ICD-10. J Clin Psychiatry 1998; 59 (suppl 20): 22-3.

21 Ventura J, Green MF, Shaner A, Liberman RP. Training and quality assurance with the Brief Psychiatric Rating Scale: 'The drift busters'. Int J Method Psych 1993; 3: 221-4

22 Derogatis LR, Melisaratos N. The Brief Symptom Inventory: an introductory report. Psychol Med 1983; 13: 595-605.

23 Zanarini MC. Zanarini rating scale for borderline personality disorder (ZAN-BPD): a continuous measure of DSM-IV borderline psychopathology. J Pers Disord 2003; 17: 233-42.

24 Budman SH, Demby A, Soldz S, Merry J. Time-limited group psychotherapy for patients with personality disorder: outcomes and dropouts. Int J Group Psychother 1996; 23: 357-77. 